2. In ten cases of hydrocephalus following cerebrospinal fever an empyema of the sphenoidal sinus was found in every case.

3 . In forty-seven completely recovered cases of cerebrospinal fever no sphenoidal empyemata were present.

REFERENCrs.
${ }^{1}$ Rolleston : Lumleian Lectures, Lancet. April 5th, 1919. 2 Embleton and Steven: Persistence of Cerebro-spinal Fever Cases as Carriers o the Meningococcus during Convalescence, Lancet, May 10th, 1919. the Medical Research Committe ${ }_{5}$ kmbleton and Rryant: Site of Carrying in Chronio 1919. 6 Peters: Proc Hoy Soc. Med vol. xii. No. 9, October 17thr Orr and Rows: Ed. Roy Soc. Med vol. Xi1, No. 9, August, 7919 8 Teale and Embleton: Joumal of Pathology. In the Press. 9 Teate and Embleton: Infection Paths of Spread in Bacterial Infection, Proc. Roy. Soc. Med., vol. vii, Path, Sect., 1914.

\section{STERILITY IN THE MALE.}

KENNETH WALKER, F.R.C.S.,

LECTURER IN VENEREAL DISEASFG AND OFFICER IN CHARGE OF VENEREAL DEPARTMENT, ST. BARTHOLOMEW'S HOSPITAI

WheN a marriage is infertilo it is still sometimes too readily assumed that the woman is at fault, although all writers on the subject recognize that the defect may rest with the husband. The object of the following summary is to emphasize the fact that no operative procedures on the wife are justifiable until the male has been properly ex amined, and until it can be definitely stated that his semen contains live, healthy, and vigorous spermatozoa.

It is difficult to obtain reliable statistics as to the fre. quency with which the male is at fault in childless mar riages. The figures given by different authorities show great discrepancies, but at any rate they indicate that the fault of the childless marriage lies far oftener with the man than is commonly supposed. Hubner, in his in vestigation of 129 childless marriages, discovered a male sterility of 59 per cent., and Kelirers, amongst 40 similar couples, one of 35 per cent. Gross, in figures collected from various authors, convicts the husband in 17 per cent of childless marriages, whilst Vedder places it as high as 70 per cent. Barney, in investigating 40 childless nnions, found 20 sterile husbands, and, what is still more sugges tive, discovered that the wives of 4 of these ( 20 per cent.) liad undergone more or less severe operations for sterility Even if the lowest of the above percentages be taken as correct, it is sufficient to support the dictum that "the investigation of childlessuess should begin not with the curettage of the wife, but with the microscopic examination of the husband's semen" (Belfield).

The investigation of sterility in the male necessitates no sinall amount of labour and skill. Such gross lesions as epispadias, hypospadias, cryptorchism, malignant disease, bilateral tuberculosis, and gummata of the testis, require no consideration beyond the noting of the fact that tuberculous epididymitis, even although it be unilateral causes azoöspermia in 85 per cent. of cases. This fact depends on the frequent association of a unilateral tubercu. lous epididymitis with disease of the prostate. It is the case where no gross lesion of the male genitalia is present that calls for careful investigation.

Whereas with the female it is Nature that plays the chief role in producing sterility, with the male the condition is more often the legacy of disease. A careful history of previous illnesses is the first step in the investigation. The orchitis of mumps, especially when it occurs about the age of puberty, is, as a rule, followed by atrophy. Fortunately such an orchitis is generally unilateral Alcoholism, exposure to $x$ rays, debilitating diseases, and sexual excesses, whether from natural coitus or masturba. tion; produce an azö̈spermia or oligospermia which is temporary in nature. Prolonged and absolute continence has been said to have a similar result (Barney). Nonvenereal infections of the testicle and prostate, whether by typhoid, Bacillus coli, or staphylococci, may similarly result in azoöspermia, oligospermia, or necrospermia, as the case may be. In a few cases it would appear that the otherwise healthy testicle of a normally active and sexually vigorous man may be entirely unproductive of spermatozoa (Janet).

But although non-venereal causes may sometimes be responsible for sterility in the male, by far the commonest cause is a previous attack of gonorrhoea. When it is remembered that in many countries the incidence of this disease is from 50 to 75 per cent. of the total adult male population, its importance as a potential cause of sterility amongst males cannot be exaggerated. All autliorities recognize the frequency with which the posterior urethra becomes implicated in gonorrhoea, and it is with posterior infections that sterility is usually associated.

The frequency with which gonorrhoea, and especially gonorrhoea affecting the posterior urethra, produces sterility is borne ont by many observers. In this con: nexion figures published by Benzler (Arch. f. Derm. unt Syph., 1898, xlv) are especially interesting. This observer followed the history of German soldiers who had suffered from gonorrhoea and had been subsequently married for three years or over. Especial attention was paid to a previous history of epididymitis.

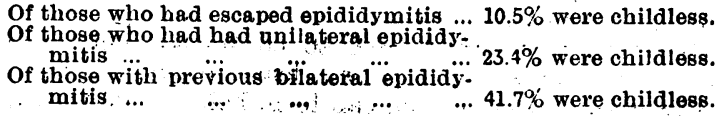

Clinical observations on the husbands of childless women with normal genitalia support these figures.: The majority of these,' when sterile, will be found to have suffered from gonococcal prostatitis, with or without epididymitis. "It is often the prostatitis rather than the epididymitis that is the determining factor, and, when the proximity iaf the ejaculatory ducts and their liability to occlusion is remembered, this is not surprising. Moreover, even when no mechanical obstruction. has been produced, pathological changes in the prostatic fluid resulting from inflammation are alone capable of producing necrospermia or oligospermia. Even healthy spermatozoa lose their vigour in the presence of pus or blood, and when, in addition to this, the activating secretions of the prostate are deficient, necrospermia and asthenospermia are extremely probable.

The second step, therefore, in the investigation of a case of male sterility is a careful and complete examination of the genitalia and urethra for evidence of past or present gonococcal infection.' 'This must invariably conclude with a urethroscopy of the posterior urethra, for it is in the presence of a prostatitis, a vesiculitis, or a colliculitis, that the explanation of sterility will often be found.

The final step in the examination includes a microscopic examination of the male secretions. As a preliminary the secretions expressed as a result of prostatic massage are subjected to examination. Attention is paid to the presence of pus cells, and the appearance of such spermatozoa as may be present is noted. This examination is, however, but a preliminary to the more detailed investigation of the seminal fluid obtained after coitus with a condom. This examination, although it gives valuable information, is unfortunately open to error. The condition of spermatozos some hours after evacuation into a condom does not necessarily reflect their condition when deposited in the vagina. For this reason Wolbarst urges the advisability of examining the vaginal and cervical secretions at various intervals after coitus has taken place. Such an examina. tion is not always obtainable, but when suitable arrange. ments can be made the results are invaluable. Details of the examination are beyond the scope of this article, but as a result of observation of the spermatozoa, witl reference to their. number, freedom from imperfect os degenerate forms, mobility, and vigour, the question of the fertility or non-fertility of the male can in the great majority of cases be put beyond doubt.

In the above summary no attempt lias been made at completeness. The subject of sterility in the male is far beyond the limits of a brief note. What has been attempted is merely to emphasize two facts which, although they may be known, are apparently too often forgotten. The first of these is the relative frequency with which sterility oecurs amongst males; the second is the lack of justification in subjecting any woman to operation for sterility unless her husband has undergone a careful preliminary examination. 